\title{
How does the one child policy impact social and economic outcomes?
}

\section{A strict policy on fertility affects every aspect of economic life}

Keywords: one child policy, fertility, human capital

\section{ELEVATOR PITCH}

The 20th century witnessed the birth of modern family planning and its effects on the fertility of hundreds of millions of couples around the world. In 1979, China formally initiated one of the world's strictest family planning programs-the "one child policy." Despite its obvious significance, the policy has been significantly understudied. Data limitations and a lack of detailed documentation have hindered researchers. However, it appears clear that the policy has affected China's economy and society in ways that extend well beyond its fertility rate.

\section{KEY FINDINGS}

\section{Pros}

$\oplus$ Due to large variation in how the one child policy was implemented across regions and ethnicities, researchers are able to exploit natural variation in their analyses, which makes empirical results reliable.

๑ Strictness of policy implementation is associated with promotion incentives for local leaders.

( The one child policy significantly curbed population growth, though there is no consensus on the magnitude.

๑ Under the policy, households tried to have additional children without breaking the law; some unintended consequences include higher reported rates of twin births and more Hanminority marriages.
One child policy fertility fine rate by Chinese province

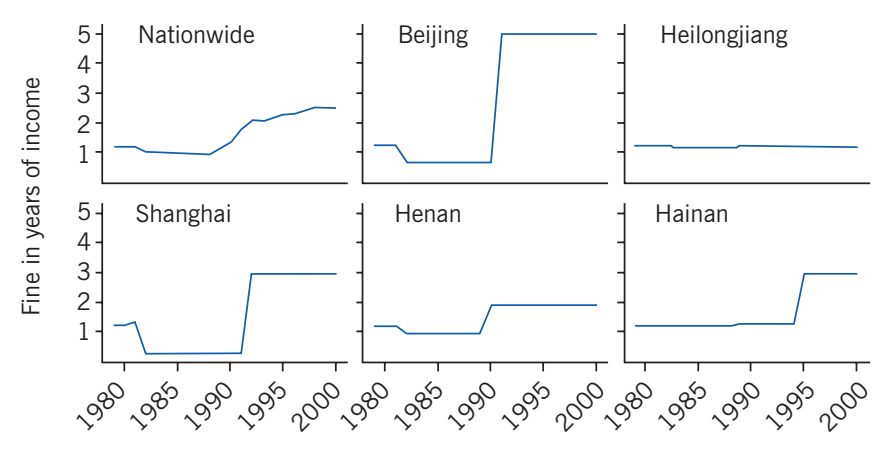

Source: [1].

\section{Cons}

- There is no solid evidence that the one child policy contributed to human capital accumulation through the traditional "quantity-quality" tradeoff channel.

- Current economic studies mainly focus on shortterm effects, while the long-term or lagged effects are substantially understudied; thus, statements about consequences and suggestions for policy designs are still missing.

- The one child policy is associated with significant problems, such as an unbalanced sex ratio, increased crime, and individual dissatisfaction toward the government.

\section{AUTHOR'S MAIN MESSAGE}

China's one child policy is possibly the largest social experiment in the history of the human race. The behavior responses to the policy offer important insights for other studies in labor, development, and public economics. To date, researchers have found that a series of outcomes, such as a lower fertility rate, an unbalanced sex ratio at birth, and higher human capital, are potentially associated with the policy. However, the answers to many important questions are far from satisfactory, and some (e.g. the long-term effects on lifecycle outcomes) have received little attention. 


\section{MOTIVATION}

The 20th century included the inception of modern family planning, which restricted the fertility of hundreds of millions of couples around the world. Due to concerns about the world's unprecedented rate of population growth in the mid-20th century, some aid agencies and international organizations began to support the establishment of family planning programs. About 40 years later, in the mid-1990s, large-scale family planning programs were active in 115 countries.

China's "one child policy" (OCP) is the largest among the world's family planning programs. In the 1970s, after two decades of explicitly encouraging population growth, policymakers in China began enacting a series of measures to curb it. The OCP was formally initiated in 1979 and firmly established across the country in 1980. It was the first time that family planning policy became formal law in China. Differing from birth control policies in many other countries, the OCP assigned a compulsory general "onebirth" quota to each couple, though its implementation has varied considerably across regions for different ethnicities at different times. The policy affected millions of couples and lasted more than 30 years. According to the World Bank, the fertility rate in China dropped from 2.81 in 1979 to 1.51 in 2000 . The reduced fertility rate is likely to have affected the Chinese labor market profoundly.

Despite its grand scope, due to data limitations, the literature on the OCP is relatively small. This article reviews some of the recent studies on the topic, with a focus on the policy's potential social and economic consequences, including consequences related to fertility, sex ratios, and education, as well as individual behavior responses, such as changes to reported twin births and interethnic marriages. By comparing the results of the existing literature and ongoing studies in China to those in other countries, it appears that the OCP has had a large and persistent impact on many aspects of society. Investigating these impacts may shed light on related issues in other realms of research, such as economics, demographics, and sociology.

\section{DISCUSSION OF PROS AND CONS}

\section{Variations in OCP implementation}

In 1979, the Chinese government formally initiated the OCP to alleviate social, economic, and environmental problems such as the high unemployment rate and scarcity of land resources. In recognition of diverse demographic and socio-economic conditions across China, the central government issued "Document 11" in February 1982 which allowed provincial governments to issue specific and locally adjusted regulations. Two years later, the central government issued "Document 7" which further stipulated that regulations regarding birth control were to be made in accordance with local conditions and were to be approved by the provincial Standing Committee of the People's Congress and provincial-level governments. This document devolved responsibility from the central government to the local and provincial governments.

As opposed to many family planning policies in other countries, the OCP was compulsory rather than voluntary. As the name suggests, the policy restricted a couple to having only one child. However, there were some exemptions. The birth quota varied according to 
residence (urban/rural) and ethnicity (Han/non-Han). Since Han ethnicity is by far the largest in China, accounting for $93 \%$ of the population, the policy mainly restricted the fertility of people with Han ethnicity. In general, Han households in urban regions were only allowed to have one child, while most households in rural areas could have a second child if their first was female (this exception is called the "one-and-a-half-child policy"). Meanwhile, in most regions, households of non-Han ethnicity were allowed to have two or three children, regardless of gender.

A frequently used measure in studies of the OCP is the average monetary penalty rate for one unauthorized birth in the province-year from 1979 to 2000. The OCP regulatory fine (which is called the "social child-raising fee" in China, and for brevity is referred to as the "policy fine" in this article) is formulated in multiples of annual income. Though the monetary penalty is only one aspect of the policy, and the government may take other administrative actions (e.g. loss of party membership or employment), it is still a good proxy for the policy because an increase in fines is usually associated with other stricter policies. The illustration on page 1 shows the pattern of policy fines from 1980 to 2000 in selected provinces and nationwide.

At the very beginning of the OCP, Vice Premier Muhua Chen proposed that it would be necessary to pass new legislation imposing penalties on unauthorized births. However, subnational leaders faced practical difficulties in collecting penalties in addition to resistance and complaints from the populace. For example, Guangdong province received more than 5,000 letters complaining about the implementation of the OCP in 1984. In response, the central government fully authorized the provincial governments to determine their own "tax rates" for excessive births with the issuance of Document 7 in 1984. Because local governments were more concerned about social stability than the central government, they had little incentive to design a high penalty rate. Consistent with the illustration on page 1, some local governments even lowered penalty rates after 1984, and, until 1989, there were few changes in fertility penalties.

A major change in fine rates occurred at the end of the 1980s though, when the central government linked the success of fertility control to promotions for local officials. As stated in the book Governing China's Population: "Addressing governors in spring $1989 \mathrm{Li}$ Peng (current premier) said that population remained in a race with grain, the outcome of which would affect the survival of the Chinese race. To achieve subnational compliance, policy must be supplemented with more detailed management by objectives (ME 890406). At a meeting on birth policy in the premier's office, Li Peng explained that such targets should be 'evaluative" [2].

In March 1991, to show resoluteness, the central government listed family planning among the three basic state policies in China's Eighth Five-Year Plan passed by the National People's Council. The Eighth Five-Year Plan explicitly set a goal of reducing the natural growth rate of the country's population to less than $1.25 \%$ on average during the following decade. To achieve such a challenging objective, national leaders employed a "responsibility system" to induce subnational or provincial officials to set high fine rates.

During the short period between 1989 and 1992, over half of the country's provinces (16 out of 30) saw a significant increase in their fine rate, with the average rate increasing from 1.0 to 2.8 times a household's yearly income. Indeed, 16 of the 21 significant increases in 
the policy's history (i.e. increases of more than one times a household's income) occurred during this period.

There is a strong correlation between increases in fine rates and the incidence of government successions. Among the 16 significant increases, 12 happened during the first two years of new provincial governors' tenures. Governors who instituted fine increases had higher chances of being promoted than their peers, and several rose to significant heights within the central government. In addition, provincial governors who increased fertility fines tended to be younger. The average age of these 16 provincial governors was 56 , which was significantly lower than the average age of other provincial governors (59 years). These numbers suggest that the promotion incentive for provincial governors could be a major driving force for the changes in fertility fines. This is also consistent with the premise that the incentive to raise fine rates depends on a governor's personal characteristics, such as inauguration time and age.

The amount collected via the policy fine was not made public until recently: the total was about 20 billion RMB yuan (US $\$ 3.3$ billion) among 24 provinces that reported fine rates in 2012. For example, Guangdong, one of the richest provinces in China, collected 1.5 billion yuan in 2012. Meanwhile, as a comparison, total local government expenditure on compulsory schooling in the province was 10.5 billion.

\section{Empirical approaches to identify the effects of the OCP}

A recent review of the literature summarizes four empirical approaches to identify the effects of the OCP [3].

The first approach uses the initial year of the policy, 1979, as a cutoff and compares the birth behaviors of women before and after implementation of the OCP. Under this approach, observations before 1979 form the control group and those after 1979 the treatment group. In general, this approach assumes there would be no change in the outcome variable (e.g. birth rate) after 1979 if there was no fertility restriction.

The second approach compares the outcomes of Han Chinese and minorities before and after policy implementation in a difference-in-differences framework. Under this approach, minorities are used as the control group and Han people as the treatment group. This methodology requires that the changes in outcome variables of Han and minorities be the same without the OCP and assumes that minorities' outcomes are not affected by the OCP. However, this requires a case-by-case analysis and one needs to be careful when drawing causal interpretations. For example, because Han-minority couples are allowed to give birth to a second child in certain regions (as shown in Figure 1), Han people have stronger incentives to marry minorities to obtain the extra birth quota. One direct consequence is a higher Han-minority marriage rate in regions with this preferential policy, as shown in Figure 2.

The third approach exploits the cross-sectional and temporal variations on fines for an illegal birth. As noted before, the fines change over time; it is thus plausible to exploit these variations to identify the effects of the fines. Unfortunately, there is no formal or accurate documentation for why the fines change. Furthermore, these changes may only reflect one aspect of the policy's effects. Therefore, further justification is required to validate the use of fines as the main independent variable. 


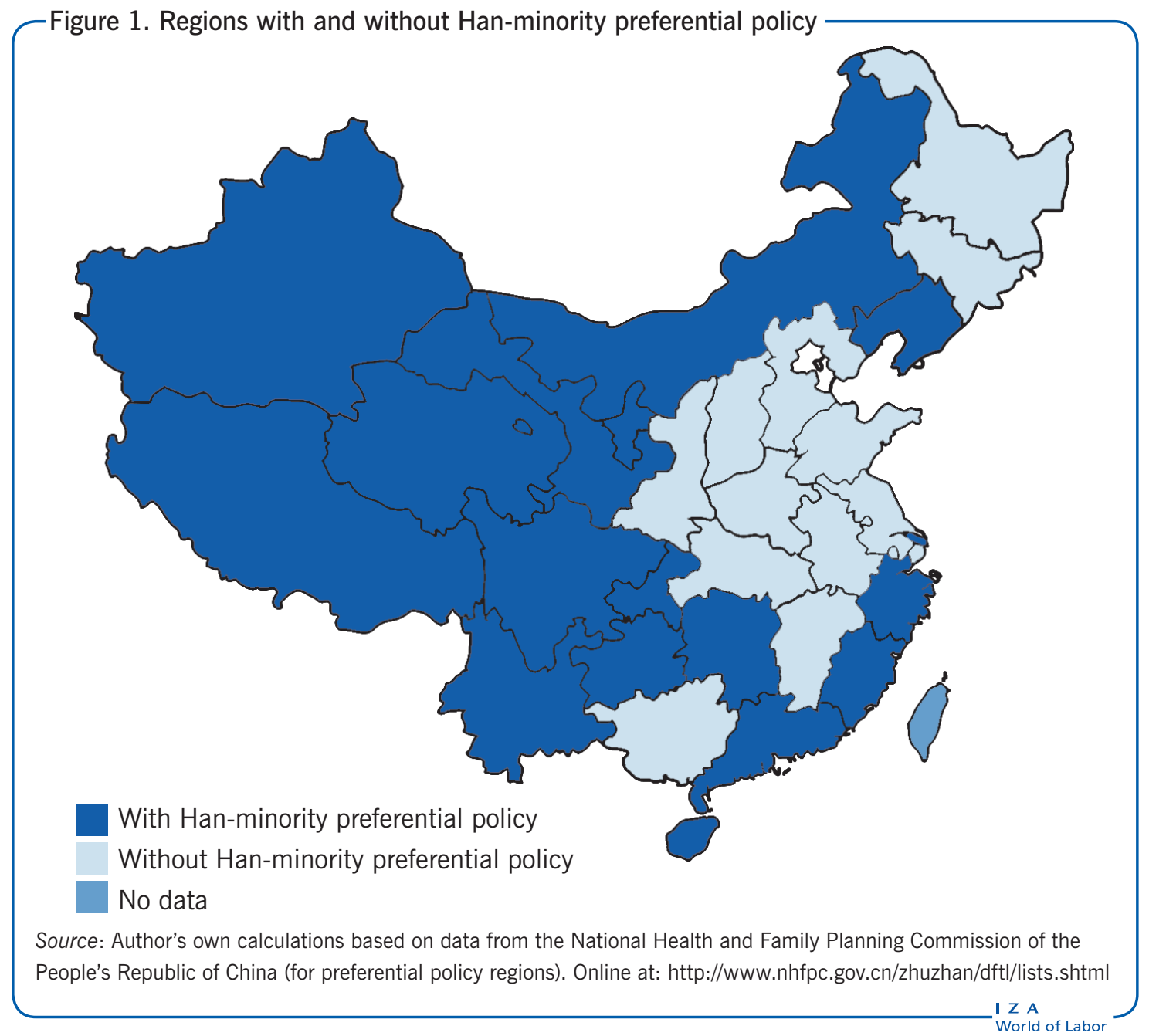

The fourth approach explores variation between the intensity of OCP implementation across different regions in combination with the differential length of exposure of different birth cohorts to the OCP. Specifically, this approach constructs a measure based on excess births to Han women over and above the one child rule in each region while controlling for pre-existing fertility and community socio-economic status. However, as noted in one recent study, this approach relies on the strong assumption that any unobserved regionspecific shocks to fertility or other family outcomes over time are uncorrelated with the cross-sectional measure of the OCP enforcement intensity [3].

It should be noted that these four approaches are not exclusive. Some ongoing projects are employing several of them at once. Given that official documentation on the policy is limited, researchers are likely to develop more empirical approaches in the future to address the current issues, such as data limitations, and gain a more complete understanding of the OCP.

\section{Effects of the OCP on fertility and the sex ratio}

Since the primary goal of the OCP was to restrict population growth, the first question to ask is whether it has been successful in this respect. The answer is generally yes, though the magnitude of its success varies according to different studies. 


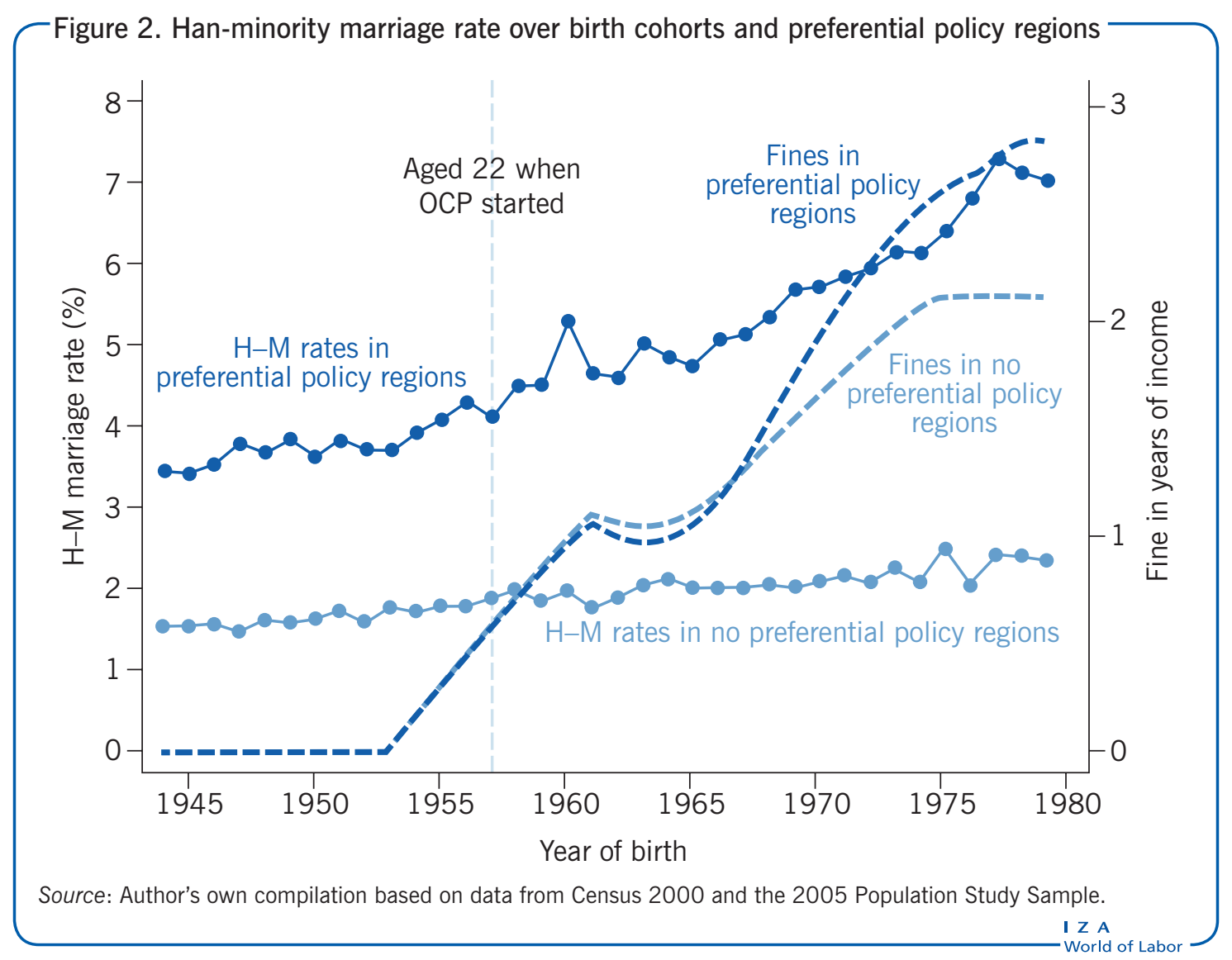

Some early studies investigated how fertility responded to the policy's restrictions [4]. Their findings are consistent, in general. For example, it was found that a one standard deviation increase in the prevalence of contraceptives led to a 0.5 standard deviation decrease in the total fertility rate.

However, the findings in the more recent literature are mixed. For instance, one study used improved measures of policy to suggest that if earlier family planning policies had not been replaced by the OCP, fertility would still have declined below the replacement level, and that the additional effects of the OCP were fairly limited [5]. By contrast, a study from 2011 used two rounds of the Chinese Population Census and found that the OCP has had a large negative effect on fertility; the average effect on posttreatment cohorts' probability of having a second child is as large as - 11 percentage points [6]. Therefore, while scholars tend to agree that the OCP has had significant effects on fertility, determining the magnitude of these effects remains an important and unanswered question.

Another demographic outcome commonly investigated in the literature is sex ratio. Incidentally correlated with the introduction of the OCP, the sex ratio at birth (i.e. males to females) increased by 0.2 over the course of 25 years, from 0.95 in 1980 to 1.15 in 2005. This phenomenon has been termed "missing women" by Amartya Sen. Since there is a strong preference for male children in China, restrictions have led to parents selecting to have/not have a child based on the results of ultrasonography technology [7]. Because parents have been able to choose abortion instead of having a girl, many researchers 
argue that the OCP has contributed to the high sex ratio in China. One study exploited the regional and temporal variation in fines levied for unauthorized births and found that higher fine regimes are associated with higher ratios of males to females [1]. The results are especially true for the second or third births: a $100 \%$ increase in the fine rate is associated with a 0.8 and 2.3 percentage point increase in the probability of having a male child in the second and third births, respectively. One of the previously mentioned studies used a different methodology, but reached a similar finding [6]. The study suggests that the effect of the OCP accounts for about $57 \%$ and $54 \%$ of the total increase in sex ratios for the 1991-2000 and 2001-2005 birth cohorts, respectively.

The imbalanced sex ratio may help to explain some puzzling phenomena in China, such as a high saving rate. In turn, this can be viewed as a possible consequence of the OCP. For example, one study found that as the sex ratio rises, Chinese parents with a son increase their savings rate in order to improve their son's relative attractiveness for marriage [8]. They find that the increase in the sex ratio from 1990 to 2007 can explain about $60 \%$ of the actual increase in the household savings rate during the same period.

Furthermore, the imbalanced sex ratio may lead to other serious social consequences, including increased crime. One study used the exogenous variation in sex ratio caused by the OCP to see its effect on crime and found an elasticity of crime with respect to the sex ratio of 16- to 25-year-olds of 3.4, suggesting that male sex ratios can account for oneseventh of the rise in crime [7]. The study proposes that one possible mechanism for this increase could be the adverse marriage market due to the unbalanced sex ratio.

\section{Effects of the OCP on human capital accumulation}

One established relationship between fertility and human capital accumulation is the child quantity-quality trade-off. However, many empirical economists have examined the relationship in the case of China and found mixed evidence. The OCP used birth quotas to control population growth. As such, it provides a potential external shock to the size of families and thus enables one to study causality between family size and children's education.

One analysis used the plausibly exogenous changes in family size caused by relaxations in the OCP to estimate the effect of the number of children in a family on school enrollment for the first child [9]. Surprisingly, the results show that having an additional child increased the likelihood of school enrollment of the first child by about 16 percentage points, implying the relationship between quantity and quality is not a "trade-off," but rather "complementary." The author provides several explanations, including greater economies of scale, enhanced permanent income, and increased labor supply of mothers.

Taking an alternate approach, another study exploited the exogenous variation in twin births in different birth orders to estimate the potential gain in human capital by policyinduced compressed family size [10]. The authors used the policy's characteristics to tell the story: producing twins on the first birth results in an exogenous shock to family size in urban regions, whereas having twins on the second birth represents an exogenous shock to family size in rural regions because parents in these areas are already allowed to have a second child. The results show a modest but positive effect of compressed family size induced by the OCP on human capital, as measured by health and education. 
The above findings suggest that the effects of the OCP on human capital are not well established when only considering the quality-quantity trade-off. For example, a study from 2010 investigated the impact of fertility policies on the socio-economic status and labor supply of women aged 15-49 years in Colombia. The results suggest that women impacted by birth control policy during their teenage years are more likely to have higher education. One possible explanation is that people are more incentivized to achieve higher education if they expect to have lower fertility. As opposed to the quality-quantity trade-off, which only affects post-policy birth cohorts, the effects from lower fertility expectations may be present among those who were born before the policy's implementation, but grew up during its tenure. This finding calls for further examination of the OCP's impact on human capital accumulation. This is important because it suggests another explanation for how fertility affects economic growth.

Discussion on the OCP's effects on human capital is still ongoing. The varied findings imply that the answer to the human capital question may depend on the individuals/cohorts examined and on the model specification employed. Although it is difficult to answer whether and to what extent the OCP increased human capital, the policy itself provides plausibly exogenous variations for future studies to examine.

\section{Effects of the OCP on other family outcomes}

Other outcomes, such as divorce, labor supply, and rural-to-urban migration have received less attention in the literature, though they are investigated in a recent study [3]. The results suggest that regions with stricter fertility policy enforcement tend to have a greater likelihood of divorce, higher male labor force participation rates, and more rural-to-urban migration; however, these effects are modest. A one standard deviation increase in policy enforcement (measured by excess fertility, as mentioned in the fourth approach presented previously) leads to a 0.015 percentage point higher divorce rate, a 0.12 percentage point higher male labor force participation rate, and a 0.8 percentage point higher rural-to-urban migration rate. The results suggest that lower birth rates may have some unintended consequences that scholars and policymakers need to consider.

Another interesting phenomenon is the increased rate of twin births. When a couple is allowed one child, the only legitimate way to have two children is to give birth to twins, which is largely out of the control of the couple. For those who do not give birth to twins, an alternative is to report fake twins, that is, to register two consecutive siblings as twins. Interestingly, the rate of twin births reported in population censuses more than doubled between the late 1960 s and the early 2000 s, from 3.5 to 7.5 per 1,000 births. A recent study suggests that at least one-third of the increase in twins since the 1970s can be explained by the OCP [11]. Since couples can intentionally have twin births to bypass the OCP (i.e. by reporting fake twins or taking fertility drugs to have multiple births), the distribution of reported twins in China may not be random.

\section{LIMITATIONS AND GAPS}

One limitation of studying the impact of the OCP may be the measures employed. Because this policy was implemented essentially at once across the entire country, little variation exists in the timing. Because of this, many scholars have relied on the differential 
treatment of Han and minority ethnicities to evaluate the policy's effects. However, this is not a perfect approach because different characteristics across the ethnicities may be correlated with the time trends, thereby biasing the results.

In addition, local governments usually had a "policy package" when implementing the OCP, which often included different penalties for illegal births for people from different backgrounds. For example, when an illegal birth is observed, those with party membership may lose it, and those hired by the public sector or collective firms may lose their jobs. These measures may go hand in hand with policy fines, but they are hard to quantify.

Furthermore, since the literature relates behavior response to social welfare, economists usually examine individuals' behavioral responses to government policies to estimate the corresponding social welfare loss. However, no study has so far examined the corresponding welfare loss for fertility policies. To do this, researchers may need to build up a model and then analyze rich data sets to provide relevant empirical evidence. However, the difficulty in this regard originates from the lack of official documentation or details regarding the implementation of China's OCP.

Finally, the current literature on the OCP mainly investigates the simultaneous or shortterm effects. Specifically, it compares how individual behaviors differ before and after the implementation of the policy. However, there is little evidence on the long-term or lagged effects of the OCP. Take the study from 2010 as an example, whose results suggest that women growing up under birth restrictions may have higher socio-economic status [12]. Considering this, the lower fertility expectations resulting from the OCP may lead to higher education, and this potentially has profound and long-lasting effects on productivity and economic growth. However, this is largely unknown in the current literature.

\section{SUMMARY AND POLICY ADVICE}

As the largest social experiment in human history, the OCP has restricted the fertility of millions of couples in China for more than three decades. This article has reviewed outcomes presented in the literature about the OCP, with a focus on its intended and unintended consequences, including fertility, sex ratio, human capital, twin births, and interethnic marriages. The results suggest that the policy has had large and long-lasting impacts on many aspects of both the economy and society, though debates persist on certain topics. The current findings also provide possible directions for insightful future studies.

It is hard to conclude whether the OCP has been good or bad in general. It has curbed the potentially problematic population boom in China, though researchers disagree as to how much of that should be attributed to the OCP, and it has possibly increased human capital accumulation. But, it has also brought with it problems, such as an unbalanced sex ratio, increased crime, and individual dissatisfaction toward the government. Since 2010, the government has loosened the policy restrictions. In late 2013, China's government started the "selective two child policy." This policy allows couples to have two children if one member of the couple has no siblings. In November 2015, the government ended the OCP and started the "universal two child policy." Although the OCP has now been terminated, there are many important questions that have yet to be answered. Until considerable further research is done, it is difficult to extrapolate lessons from China's experience to inform future policy decisions. 


\section{Acknowledgments}

The author thanks an anonymous referee and the IZA World of Labor editors for many helpful suggestions on earlier drafts. Previous work of the author contains a larger number of background references for the material presented here and has been used intensively in all major parts of this article [11].

\section{Competing interests}

The IZA World of Labor project is committed to the IZA Guiding Principles of Research Integrity. The author declares to have observed these principles.

(c) Wei Huang 


\section{REFERENCES}

\section{Further reading}

Feng, W., Y. Cai, and B. Gu. "Population, policy, and politics: How will history judge China's onechild policy?" Population and Development Review 38:s1 (2013): 115-129.

$\mathrm{Li}, \mathrm{B}$., and H. Zhang. "Does population control lead to better child quality? Evidence from China's one-child policy enforcement." Journal of Comparative Economics 45:2 (2017): 246-260.

\section{Key references}

[1] Ebenstein, A. "The missing girls of China and the unintended consequences of the one child policy." Journal of Human Resources 45:1 (2010): 87-115.

[2] Greenhalgh, S., and E. A. Winckler. Governing China's Population: From Leninist to Neoliberal Biopolitics. Stanford, CA: Stanford University Press, 2005.

[3] Zhang, J. "The evolution of China's one-child policy and its effects on family outcomes." Journal of Economic Perspectives 31:1 (2017): 141-160.

[4] Poston, D. L., and B. Gu. "Socioeconomic development, family planning, and fertility in China.” Demography 24:4 (1987): 531-551.

[5] Wang, F., L. Zhao, and Z. Zhao. "China's family planning policies and their labor market consequences." Journal of Population Economics 30:1 (2017): 31-68.

[6] Li, H., J. Yi, and J. Zhang. "Estimating the effect of the one-child policy on the sex ratio imbalance in China: Identification based on the difference-in-differences." Demography 48:4 (2011): 1535-1557.

[7] Edlund, L., H. Li, J. Yi, and J. Zhang. "Sex ratios and crime: Evidence from China." Review of Economics and Statistics 95:5 (2013): 1520-1534.

[8] Wei, S.-J., and X. Zhang. "The competitive saving motive: Evidence from rising sex ratios and savings rates in China." Journal of Political Economy 119:3 (2011): 511-564.

[9] Qian, N. Quantity-Quality and the One Child Policy: The Only-Child Disadvantage in School Enrollment in Rural China. NBER Working Paper No. 14973, 2009.

[10] Rosenzweig, M. R., and J. Zhang. "Do population control policies induce more human capital investment? Twins, birth weight and China's one-child policy." The Review of Economic Studies 76:3 (2009): 1149-1174.

[11] Huang, W., X. Lei, and Y. Zhao. "One-child policy and the rise of man-made twins." Review of Economics and Statistics 98:3 (2016): 467-476.

[12] Miller, G. "Contraception as development? New evidence from family planning in Colombia." The Economic Journal 120:545 (2010): 709-736.

\section{Online extras}

The full reference list for this article is available from:

http://wol.iza.org/articles/how-does-the-one-child-policy-impact-social-and-economic-outcomes

View the evidence map for this article:

http://wol.iza.org/articles/how-does-the-one-child-policy-impact-social-and-economic-outcomes/map 